\title{
A COMUNICAÇÃO HUMANO-AUTOMAÇÃO: IMPACTOS NO COMPORTAMENTO DE VIGÍLIA DO USUÁRIO DE SISTEMAS AUTOMATIZADOS
}

\section{THE HUMAN-AUTOMATION COMUNICATION: IMPACTS ON AUTOMATION USERS`VIGILANT BEHAVIOUR}

\author{
Rafael Cirino Gonçalves, Mestrando, Bolsista Capes \\ Manuela Quaresma, D.Sc. \\ (1) LEUI | Laboratório de Ergodesign e Usabilidade de Interfaces - PUC-Rio \\ email: rafaelcirinogoncalves@gmail.com \\ (2) LEUI | Laboratório de Ergodesign e Usabilidade de Interfaces - PUC-Rio \\ email:mquaresma@puc-rio.br
}

Interação humano-automatização, Complacência, Comportamento do usuário

\begin{abstract}
O objetivo deste artigo foi realizar uma análise teórica do fenômeno da complacência do usuário de sistemas automatizados sob a perspectiva da teoria de detecção de sinais e do behaviorismo radical. Buscou-se com isso entender o papel do design de interação na formação do comportamento de vigília do usuário durante uma tarefa automatizada. Os resultados deste estudo apontam para um impasse teórico que impossibilita a generalização de uma abordagem ideal de interface para a construção de sistemas autônomos. Conclui-se que uma comunicação constante pode levar à saturação dos estímulos de interface, da mesma forma que uma comunicação discreta pode levar a uma extinção do comportamento de vigília do usuário. Novos estudos empíricos são necessários para modelar o fenômeno nos diferentes casos específicos em que se aplica.
\end{abstract}

\section{Human-Automation Interaction, Complacency, Users' Behavior}

The goal of this paper was to conduct a theoretical analysis of the phenomenon of users' complacency over automated systems in the perspective of the signal detection theory and the radical behaviorism. This study looked for the comprehension of the role of interaction design in users' vigilant behavior during an automated task. The results pointed out to a theoretical conflict that impedes the generalization for the best practices in automation interface design. It can be concluded that constant communication can lead to the saturation of the interface stimuli, in the same way, a more discrete communication approach can lead to a behavioral extinction of the vigilant behavior. More empirical studies are needed to model the different cases applicable.

\section{Introdução}

A chegada de sistemas automatizados tem trazido novos paradigmas para a área da ergonomia, principalmente no que tange o papel do humano no desenvolvimento da tarefa. De acordo com Parasuraman \& Sheridan [2006], a inserção de
Realização:

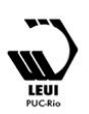




\section{$16^{\circ}$ \\ ERGODESIGN USIHC CINAHPA}

elementos automatizados faz com que o humano deixe de ser o realizador operacional da tarefa e assuma um papel supervisório de vigília do funcionamento do sistema. Dentro desta lógica, o usuário precisa estar atento à atividade do sistema para identificar anomalias e poder intervir corretamente caso preciso.

De acordo com a teoria de deteç̧ão de sinais (SDT - Signal Detection Theory) em Ritter et al. [2014], a capacidade humana de atentar para sinais e elementos providos pelo ambiente está sobre constante mutação baseada nas condições em que o indivíduo se encontra, de forma a necessitar de um estímulo uma maior ou menor intensidade para que se torne uma saliência. Adequando esta teoria ao escopo da automação, é de se entender que a capacidade de um usuário de identificar uma anomalia no sistema pode variar ao longo da tarefa a depender dos cenários que lhe forem apresentados.

Parasuraman \& Dietrich [2010] afirmam que após longa exposição a uma tarefa automatizada, a capacidade de vigília de um usuário é gradativamente reduzida, fenômeno este chamado de complacência. Skinner [1953] define a atenção como a capacidade de uma pessoa para reagir a um estímulo apresentado pelo ambiente. $\mathrm{O}$ autor também afirma que quando tal comportamento não é devidamente estimulado, acaba se extinguindo. Em outras palavras, a retirada das funções operacionais de uma pessoa dentro de uma tarefa, caso não seja devidamente remediada, acaba por reduzir as capacidades de vigília do usuário sob o funcionamento do sistema automatizado.

Dentro dessa lógica, versa-se a favor da ideia que uma interface de comunicação humano-automação bem projetada pode colaborar para a redução do fenômeno de complacência do usuário, uma vez que o mesmo pode garantir um estímulo constante à percepção do usuário sobre a tarefa. Da mesma forma, uma série de alertas incoerentes ou excessivos podem saturar a percepção de um determinado fenômeno e acelerar o processo de complacência.

Este artigo apresenta uma reflexão teórica sobre o $16^{\circ}$ Ergodesign - Congresso Internacional de Ergonomia e Usabilidade de Interfaces Humano Tecnológica: Produto, Informações Ambientes Construídos e Transporte

$16^{\circ}$ USIHC - Congresso Internacional de Ergonomia e Usabilidade de Interfaces Humano Computador

CINAHPA | 2017 - Congresso Internacional de Ambientes Hipermídia para Aprendizagem.

uso de alertas de sistemas automatizados para a redução da complacência do usuário a luz de duas bases teóricas: A teoria de detecção de sinais e o Behaviorismo radical.

\section{TEORIAS PARA A COMUNICAÇÃO HUMANO-AUTOMAÇÃO}

\subsection{HAI - Interação Humano-Automação (Human Automation Interaction)}

Por definição, sistemas a automatizados são aqueles que realizam tarefas de forma completa ou parcialmente sem a necessidade direta de atividade humana no processo [PARASURAMAN \& SHERIDAN, 2006]. Dentro deste conceito, é de se entender que a máquina - ou sistema automatizado - assume o papel operacional da tarefa, realizando atividades laborais com precisão e agilidade muito acima da capacidade humana. Em contrapartida, de acordo com Norman [2009] e Wickens et al. [2010], tais sistemas carecem de capacidades de tomada de decisão por não contarem com um potencial de abstração semântica para leitura crítica de situações complexas. Em outras palavras, leituras numéricas de sensores não são capazes de modelar os diferentes cenários em que devem atuar, e por sua vez, julgar qualitativamente quais passos devem ser seguidos para o bom andamento da tarefa em cada situação -principalmente em casos de falha mecânica ou emergência. Em contrapartida, o humano/usuário deste sistema, apesar de não possuir capacidades motoras para realizar a tarefa por si só com a mesma eficiência, possui plenas capacidades de pensamento crítico e estratégico. Esta especificidade faz com que, diferentemente do que se estuda tradicionalmente em ergonomia [MORAES \& MONT'ALVÃO, 2012; CHAPANIS, 1962; PROCTOR \& VU, 2006; FITTS, 1959 apud. SALVENDI, 2006], o humano assuma o papel de supervisor estratégico do bom andamento da tarefa.

Parasuraman \& Sheridan [2006] e Dekker [2004] definem este novo paradigma de interação como paradigma do controle supervisório (supervisory control paradigm), tal qual define estritamente os
Realização:
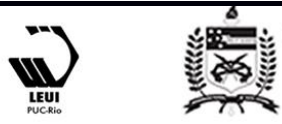


\section{$16^{\circ}$ \\ ERGODESIGN USIHC CINAHPA}

$16^{\circ}$ Ergodesign - Congresso Internacional de Ergonomia e Usabilidade de Interfaces Humano Tecnológica: Produto, Informações Ambientes Construídos e Transporte

$16^{\circ}$ USIHC - Congresso Internacional de Ergonomia e Usabilidade de Interfaces Humano Computador

CINAHPA | 2017 - Congresso Internacional de Ambientes Hipermídia para Aprendizagem. papéis de cada um dos indivíduos - humano e automação - dentro da tarefa, baseado em suas capacidades e limitações. Sob a perspectiva do usuário, o estado de controle supervisório pode ser subdividido em 5 passos [PARASURAMAN \& SHERIDAN, 2006; DEKKER, 2004]: a) planejamento da atividade offline; b) programação e orientação do sistema; c) monitoramento do sistema automatizado durante a execução da tarefa; d) interferência na ação do sistema (caso haja algum erro de funcionamento); e) aprendizado com a experiência. Dentro da perspectiva do sistema automatizado, pesquisadores [YOUNG, 2013; DEGANI, 2003; HSE, 2003; PARASURAMAN \& SHERIDAN, 2006] definem etapas similares para o seu funcionamento operacional, sendo elas: a) observação de uma variável; b) orientação desta variação de acordo com os limiares relevantes; c) decisão da ação necessária de acordo com o cenário observado; d) execução da ação.

Analisando a interação entre cada um dos processos, fica evidente que todas as etapas de ambos os lados estão intimamente interligadas, de forma que a falha em qualquer um dos processos de ambas as partes - humano e automação compromete severamente o andamento da tarefa. Ou seja, caso o sistema apresente problemas e o usuário seja incapaz de percebê-los, a tarefa como um todo fica comprometida. Norman [2009] defende que qualquer sistema automatizado é passível de eventual falha e não tem como perceber seus próprios erros, necessitando de uma intervenção do usuário em momentos críticos. O problema nesta relação se faz presente a partir do momento em que o usuário falha na sua função de vigília. Como já afirmado por Jones [2007, p. 12]: "Infelizmente, humanos não são especialmente bons em manter um monitoramento passivo de sistemas automatizados por um longo período de tempo". Dado este problema, é de se entender que o uso de sistemas automatizados acaba por induzir a redução da vigília sobre a atividade em questão. Uma vez que os sistemas assumem determinada função operacional relacionada à tarefa, a demanda de atenção para o usuário é reduzida.

São muitos os estudos que observam o fenômeno da redução das habilidades de vigília do usuário de sistemas automatizados após seu uso prolongado, fenômeno este chamado de complacência [WICKENS et al., 2010; PARASURAMAN et al., 2000]. Mouloua, Parasuraman \& Molloy [1993];

Parasuraman, Mouloua \& Molloy [1996]; Hilburn, Parasuraman \& Moulouna [1996]; Oakley, Moulouna \& Hancock [2003] e Jones [2007] chegaram a resultados importantes que revelam que o grau de confiabilidade do produto aliado ao nível de autonomia do sistema automatizado apresentam estreita relação com perda gradual da capacidade do usuário de manter o foco na tarefa desempenhada. A complacência pode ser vista em atividades simples do dia a dia das pessoas na relação com sistemas automatizados, seja ao confiar em um despertador de um celular sem conferir se está ligado ou ajustado para a hora certa, ou na qualidade de uma maquina de lavar roupa, sem conferir se há algum transbordamento ou falta de material. Da mesma forma, tal fenômeno se abate de forma crítica em interações mais complexas, como no controle de carros autônomos (como os desenvolvidos pela Google.inc ou Tesla.inc), ou na aviação, onde a apatia é constante e uma pequena falha no processo de vigília pode promover riscos de vida ao usuário.

Uma vez que a tarefa de vigília do usuário ocorre mediante a observação de elementos e alertas provenientes de uma interface de comunicação entre o humano e o sistema, faz-se necessário modelar o fenômeno da complacência diante da interação com tal interface. Nesta perspectiva, salienta-se o importante papel dos estímulos à atenção e alertas oferecidos pelo sistema na modelagem do comportamento de vigília do usuário.

\subsection{SDT - Teoria de Detecção de Sinais (Signal Detection Theory)}

Para melhor entender como interagimos com elementos automatizados, precisa-se entender como o ser humano interage com sinais, mensagens e qualquer outro tipo de comunicação exercida entre eles e máquinas. uma das áreas da ergonomia cognitiva que estuda este fenômeno chama-se teoria de detecção de sinais ou SDT (signal detection theory) [RITTER et al.;2014]. De
Realização:

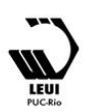




\section{$16^{\circ}$ \\ ERGODESIGN USIHC CINAHPA}

acordo com Ritter et al. [2014] para cada um dos cinco sentidos do ser humano existe um limiar de variação de estímulo que o faz ser percebido, ou seja, capaz de atrair a atenção do receptor e se distinguir da normalidade das informações presentes dentro de um mesmo canal sensitivo. Tais limiares de estímulo são chamados de saliências perceptivas ou JND (just noticeable differences). JNDs podem ser definidos como a menor porção de variação de estímulo dentro de um canal sensitivo para que possa ser percebido pelo receptor [RITTER et al.; 2014]. Por exemplo, em caso de um feedback sonoro oferecido pela interface de um sistema automatizado, para cada pessoa existe um limite mínimo de decibéis/distância necessário para que o som emitido se diferencie da nuvem de ruídos do ambiente e se faça perceptível para o usuário. $\mathrm{O}$ mesmo se faz presente em termos de variação de cor e luminescência para feedbacks visuais ou o torque/newtons por centímetro cúbico em caso de feedbacks tácitos.

Relacionando tal teoria com o processo de complacência do usuário, pode-se assumir que tal limite de cada uma das JNDs não é estanque. $\mathrm{O}$ mesmo está sujeito a uma série de variáveis que podem interferir na intensidade necessária para que tal limiar seja atingido. Pode-se então afirmar que a eficiência e eficácia de qualquer estímulo é dependente do contexto em que é inserido, uma vez que está sujeito a variação em seus limiares de percepção de acordo com backgrounds do usuário, esforço cognitivo exercido pelo receptor,

complexidade do sinal, estresse entre outros. Todos estes fatores que podem vir a comprometer a boa deteç̧ão de determinado sinal é chamado de ruído (noise). Em casos onde o usuário do sistema realiza mais de uma atividade ao mesmo tempo como o monitoramento de mais de um sistema- a própria atividade paralela realizada pode ser uma barreira para a percepção dos alertas e avisos provenientes do sistema. Estas barreiras podem levar a falhas no processo de vigilância do usuário, tornando-o sujeito a eventuais problemas no bom andamento da tarefa. Para ilustrar este fenômeno, podemos entender que o operador de uma planta automatizada pode deixar de observar um determinado alerta de segurança por estar ocupado com outras demandas. Como o evento crítico para o qual deve atentar é extremamente raro, é de se entender que o operador desvie gradativamente a sua atenção para outras tarefas, aumentando o limiar perceptivo necessário para atentar a tal alerta. Tal caso pode ser observado em HSE [2007]. Ritter et al. [2014] afirmam que quando determinado estímulo é apresentado diversas vezes ao mesmo receptor, existe uma tendência de seu limiar perceptivo aumentar gradativamente, uma vez que o mesmo entra no senso comum, se assimilando à nuvem de ruídos apresentada pelo ambiente, e não mais se tratando de uma saliência. Em casos onde o ambiente da tarefa traz outras demandas ao usuário, os estímulos repetitivos da interface do sistema podem passar despercebidos, justamente por muitas vezes não necessitar de uma factual intervenção, apenas sinaliza o funcionamento padrão do sistema. Tal processo é chamado pelos autores de habituação. Diversos autores como Jones [2007]; wickens [2010] e Prinzel [2001], comprovam que a exposição contínua de usuários a estímulos intermitentes durante um estado de monitoramento passivo da interface compromete a capacidade de atentarem para informações relevantes em situações de risco. Tais autores constatam em suas pesquisas que a inatividade operacional mediante a um estímulo apresentado fez com que os sujeitos passassem gradativamente a ignorar os mecanismos de comunicação das interfaces.Nos experimentos de Jones [2007], observou-se que pilotos de aviões comerciais perdem seu foco na interface de bordo devido ao tédio e a inatividade que se abate durante todo o voo.

De acordo com Ritter et al. [2014], a SDT caracteriza quatro tipos diferentes de fenômenos perceptivos (descritos da na figura 1). Quando determinado estímulo é percebido e se faz presente (é real), ou seja, é corretamente percebido, o mesmo é chamado de acerto. Quando algum sinal saliente não é percebido, apesar de existir, é chamado de falha. Quando algum estímulo se torna consciente porém sem existir realmente (geralmente quando o ruído é confundido com algum real sinal), é chamado de alarme falso. Quando algum estímulo se faz inexistente e não é percebido, o mesmo é chamado de rejeição correta.
Realização:

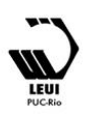




\section{$16^{\circ}$ \\ ERGODESIGN USIHC CINAHPA}

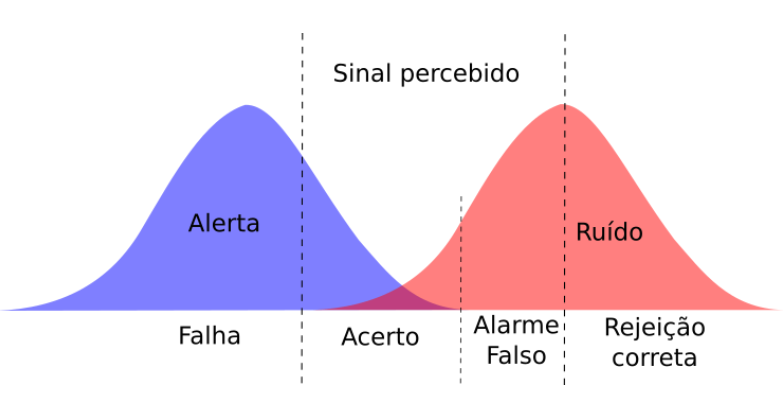

1 Esquema da teoria de detecção de sinais [Ritter et al., 2014] (tradução do autor)

Cabe aqui salientar o fator fenomenológico comportamental da SDT, uma vez que cada alarme falso, ou qualquer outro tipo de sinal percebido ou não pelo receptor serve de reforçador comportamental para ajuste dos limiares perceptivos de cada um. Ritter et al. [2014] afirmam que o custo de alarmes falsos e falhas influenciam diretamente no ponto em que o limiar se estabelece em cada individuo. Quando não percebemos algo que deveríamos ter percebido, ficamos mais atentos ao fato, ou quando vemos algo que não existe, tendemos a ser menos cuidadosos a determinado estímulo, de forma que, aos poucos, cada evento nos condiciona a determinar diferentes limiares perceptivos. Ao analisarmos a relação humano automação, podemos considerar momentos de chamada de atenção não emergenciais como alarmes falsos, que acabam aumentando desnecessariamente o limiar perceptivo de um alerta de situação crítica. Lyons et al. [2016] alertam desenvolvedores de interface para o perigo da resignificação dos elementos de comunicação de interface, que quando excessivos, passam a se tornar incômodos e perdem a sua função comunicativa. Durante os experimentos realizados pelo autor, pilotos de aviação militar relataram que alertas repetitivos - e que não exigiam atividades diferentes das que já estavam realizando, eram inconvenientes, então, eram rapidamente ignorados.

\subsection{Discriminação operante e extinção comportamental}

Entendendo o estado supervisório do usuário de sistemas automatizados numa perspectiva comportamental, podemos considerar a vigilância $16^{\circ}$ Ergodesign - Congresso Internacional de Ergonomia e Usabilidade de Interfaces Humano Tecnológica: Produto, Informações Ambientes Construídos e Transporte

$16^{\circ}$ USIHC - Congresso Internacional de Ergonomia e Usabilidade de Interfaces Humano Computador

CINAHPA | 2017 - Congresso Internacional de Ambientes Hipermídia para Aprendizagem.

um produto de um fenômeno largamente estudado: a atenção. Skinner [1953] e Reynolds \& Limpo [1969] definem a atenção como o a capacidade de um indivíduo de reconhecer, discriminar e responder a um estímulo apresentado pelo ambiente em meio a uma série de outros presentes em concomitância. Tais autores descrevem o fenômeno como discriminação operante, ou seja, o condicionamento constante de um comportamento de distinção de um elemento específico, evocando o operante de atenção. Ray [1972] também descreve atenção como a fração mais irredutível da relação estímulo-resposta condicionada. Dentro do contexto da interação humano-automação, pode-se considerar este fenômeno como o comportamento condicionado do usuário de diferenciar um elemento de uma interface em meio a uma nuvem de ruído -como já definido anteriormente- e responder a ele de acordo com seu repertório.

Ao considerarmos o fenômeno da atenção como um comportamento de discriminação, faz-se necessário destacar a importância do processo de caracterização dos estímulos e os fatores que condicionam a ocorrência deste comportamento. Skinner [1953] desenvolveu importantes tratados que afirmam que a atenção é um comportamento processualmente construído. Ray [1972] afirma que a atenção de um indivíduo não pode ser dissociada do estímulo que a evoca, ou das suas condições de ocorrência. $\mathrm{O}$ autor defende que não existe uma capacidade genérica de se atentar a elementos em um ambiente. Uma mesma pessoa pode apresentar diferentes capacidades de vigília para elementos e ou condições distintas, referentes ao condicionamento prévio deste comportamento. Pelo mesmo motivo, atenção não é uma virtude que pode ser treinada e desenvolvida de forma abrangente, mas sim modelada dentro de condições específicas. Em outras palavras, um usuário de sistema pode ser condicionado a sempre observar um elemento crítico em uma interface de sistema automatizado, porém, à medida que novos cenários são apresentados ao indivíduo, esta capacidade de resposta pode se alterar. Acredita-se que a inserção de elementos automatizados, como descrito anteriormente, seja um elemento condicionador do comportamento complacente, o que dialoga com os estudos de Parasuraman \& Molloy [1993];
Realização:
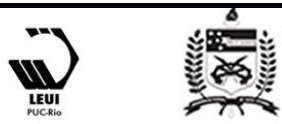


\section{$16^{\circ}$ \\ ERGODESIGN USIHC CINAHPA}

Parasuraman, Mouloua \& Molloy [1996]; Hilburn, Parasuraman \& Moulouna [1996]; Oakley, Moulouna \& Hancock [2003] e Jones [2007]. Um exemplo ilustrativo deste fenômeno pode ser descrito na interação de um motorista com um sistema de controle de curso (cruise control). Uma vez que o sistema assume a responsabilidade sobre a velocidade do veículo, o motorista deixa de olhar para o velocímetro, estando sujeito a falhas e acelerações indevidas.

Skinner [1953], afirma que o comportamento operante de um individuo pode ser evocado através de um processo discriminante de suas condições de ocorrência. Em outras palavras, o comportamento se constrói a partir do momento em que o indivíduo é exposto às consequências e condições referentes à ação praticada. Dentro deste processo de condicionamento do comportamento operante, o autor descreve dois tipos de estímulos que participam de tal processo (esquematizados na figura 2):

- $\quad$ Estímulos reforçadores - são estímulos que, quando ocorridos em seguida do operante, aumentam sua probabilidade de ocorrer em condições iguais ou semelhantes. Eles podem ser tanto positivos, definindo-se como a adição de um estímulo, quanto negativos, definindo-se como agentes de retirada de uma condição aversiva.

- $\quad$ Estímulos aversivos - estímulos envolvidos no processo ativo de diminuição de probabilidade de resposta. A saber, a punição, que é definida pela sua função e não pela forma na qual é feita.

Quando apresentadas em seguida de um operante, pode reduzir a sua ocorrência

\begin{tabular}{|c|c|c|}
\hline operação & Estímulo (s) (+) & Estímulo (s) ( $)$ \\
\hline efeito & $\begin{array}{c}\text { Reforçamento }+ \\
\text { (S apetitivo) }\end{array}$ & $\begin{array}{c}\text { Reforçamento - } \\
\text { (S aversivo) }\end{array}$ \\
\hline $\begin{array}{l}\text { Probabilidade } \\
\text { de resposta (R) }\end{array}$ & Punição + & Puniçào - \\
(S apetitivo)
\end{tabular}

2 Esquema de estímulos comportamentais $16^{\circ}$ Ergodesign - Congresso Internacional de Ergonomia e Usabilidade de Interfaces Humano Tecnológica: Produto, Informações Ambientes Construídos e Transporte

$16^{\circ}$ USIHC - Congresso Internacional de Ergonomia e Usabilidade de Interfaces Humano Computador

CINAHPA | 2017 - Congresso Internacional de Ambientes Hipermídia para Aprendizagem.
[HUNZIKER, 2011] (adaptação do autor). ${ }^{1}$

Nesta linha de raciocínio, podemos entender a retirada de funções operacionais do humano na relação com sistemas automatizados como um estímulo aversivo ao processo de vigília, justamente por uma queda de demanda, gerando tédio e apatia. Jones [2007], evidenciou o impacto da retirada de funções de usuários na sua capacidade de vigília, constatando que cerca de 20 minutos de apatia são suficientes para o surgimento gradual de uma complacência sobre a vigília dos processos automatizados. Da mesma forma, podemos compreender os elementos de comunicação da interface, quando devidamente caracterizados como reforçadores de um comportamento vigilante, uma vez que a chamada de atenção exige uma intervenção operacional no andamento da tarefa, evidenciando a necessidade de percepção do mesmo estímulo em momentos subsequentes. Marstall et al. [2016]; Lyons et al. [2016] e Banks \& Stanton [2016] apresentam uma série de vantagens da comunicação constante do status do sistema ao usuário, garantindo uma maior transparência e confiança, que podem vir a melhor discriminar os cenários onde ele deve interferir na operação do sistema.

Como já dito anteriormente, a atenção é um comportamento de construção processual, condicionado, e por este motivo, caso não seja devidamente reforçado ao longo do tempo evidenciando os estímulos e sua resposta operante-, o mesmo tende a uma gradual extinção. Skinner [1953] e Reynolds \& Limpo [1969] definem extinção comportamental como a redução da probabilidade de ocorrência de uma resposta mediante a apresentação de um estímulo, e no caso da atenção, o indivíduo se tornará incapaz de diferenciar determinado elemento da interface quando apresentado. Reynolds \& Limpo [1969] alegam que o intervalo da intermitência do reforço a determinado operante, assim como a consistência entre o estímulo e o reforçador, são de suma importância para a manutenção da frequência de determinado comportamento. Caso os eventos a

\footnotetext{
${ }^{1}$ Entende-se na imagem $\mathrm{S}$ apetitivo como reforçador, segundo a teoria de Skinner [1953].
}

Realização:

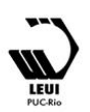




\section{$16^{\circ}$ \\ ERGODESIGN USIHC CINAHPA}

$16^{\circ}$ Ergodesign - Congresso Internacional de Ergonomia e Usabilidade de Interfaces Humano Tecnológica: Produto, Informações Ambientes Construídos e Transporte

$16^{\circ}$ USIHC - Congresso Internacional de Ergonomia e Usabilidade de Interfaces Humano Computador

CINAHPA | 2017 - Congresso Internacional de Ambientes Hipermídia para Aprendizagem. serem percebidos sejam muito espaçados - ou um mesmo estímulo da interface possa indicar dois eventos diferentes, a percepção do usuário é gravemente comprometida. Lyons et al. [2016] demonstram em seus experimentos que falhas em alertas ou inconsistências de sinal tiveram impacto direto na relação de usuários com seus respectivos sistemas automatizados.Este fenômeno novamente remete ao caso de pilotos de avião, que deixam de atentar aos controles de bordo devido a uma apatia, ou a um sinal errado apresentado pelo sistema.

\subsection{Design de interação e a vigília do usuário}

Podemos entender a retirada das funções operacionais do usuário como um estímulo aversivo -ou a retirada de um estímulo à atenção, que seria o próprio ato de interferência na tarefa. Isto faz com que a única fonte de estímulos à atenção do usuário sejam os alertas e sinais da interface. Dentro desta perspectiva, caso a comunicação não ocorra de forma devidamente constante - discriminando os estímulos para o operante de agir, o processo de observação da própria interface vai se extinguindo até que os limiares de JND não sejam compatíveis com a intensidade dos estímulos da interface.

Por estes motivos, segundo as teorias apresentadas acima, o usuário deve atentar para os estímulos de uma interface na busca por eventuais falhas no funcionamento do sistema automatizado. Porém, devido ao seu baixo grau de ocorrência, muitas vezes a própria comunicação dos processos operacionais por parte da interface pode ser entendida como um alarme falso. Em outras palavras, à medida que a interface comunica ao usuário sobre seu funcionamento- porém sem nenhuma informação que exija alguma intervenção, esta apatia por sua vez acaba se tornando um estímulo aversivo ao próprio operante de observar o funcionamento da interface, fazendo o usuário cada vez menos apto a atentá-lo.

Banks \& Stanton [2016]; HSE [2007]; Carvalho et al. [2008]; Marstall et al. [2016]; e Lyons et al. [2016] salientam a necessidade de um maior cuidado na concepção na interfaces de comunicação entre sistemas automatizados e seus usuários, considerando a natureza das tarefas, necessidades dos usuários e as barreiras impostas pelos sistemas. Com base nos argumentos acima, é seguro afirmar que a interface de comunicação humano-máquina desempenha um papel de suma importância para a formação das capacidades de vigília do usuário. Como os estímulos e reforçadores para o comportamento de vigília provêm da interface, tomadas de decisão mais assertivas ou errôneas podem comprometer ou favorecer o bom andamento da tarefa.

\section{DISCUSSÃO}

O objetivo deste estudo foi realizar uma comparação teórica de duas teorias que modelam o fenômeno da complacência do usuário com sistemas automatizados, no intuito de identificar o papel do design de interação no processo de formação da vigília do humano. Evidenciou-se que o processo em si de supervisão de um sistema automatizado leva á complacência, que nada mais é do que o aumento do limiar perceptivo do usuário para os sinais oferecidos pela interface. A literatura apresentada demonstra que este é um processo natural, proveniente da retirada das atividades operacionais do usuário, que por si só age como um estímulo aversivo ao comportamento de vigília.

Evidenciou-se também que o processo de percepção de anomalias dentro do estado de controle supervisório está completamente em função dos estímulos oferecidos ou não à atenção do usuário. uma vez que eles são os únicos reforçadores do comportamento de monitoramento da atividade do sistema automatizado. Devido a este fato, fica claro que uma comunicação mais discreta entre a interface e o usuário pode reduzir o número de alarmes falsos oferecidos, porém, a falta de estímulos à atenção colabora para a extinção comportamental da vigília de processos. Da mesma forma, um número maior de alertas de comunicação dos processos de tomada de decisão do sistema pode colaborar para a manutenção do comportamento operante de observa-lo, porém, o consequente aumento do número de alarmes falsos registrado pode tornar a comunicação da interface 


\section{$16^{\circ}$ \\ ERGODESIGN USIHC CINAHPA}

um fator de incômodo, descaracterizando sua natureza informacional.

Pode-se então afirmar que existe um impasse teórico no que tange as diferentes abordagens de interface para a comunicação humano-automação. Uma vez que uma comunicação constante tende a uma saturação de estímulo e uma comunicação discreta tende à extinção do comportamento de vigília, é seguro constatar que é necessário um balanço na frequência de sinais apresentados pelas interfaces, de forma que este processo não é generalizável. Se a teoria por si só não é capaz de modelar um padrão de abordagem para tal assunto, cada caso deve ser analisado individualmente.

\section{CONCLUSÃO}

Ao final desta revisão de literatura, pôde-se concluir que o design de interação com sistemas automatizados possui um papel de suma importância na modelagem do comportamento de vigília do usuário. Apesar deste achado, não foi possível concluir um padrão ideal de abordagem que melhor atenda as necessidades do contexto da interação humano-automação. Maiores estudos são necessários para avaliar empiricamente o impacto das diferentes abordagens de design de interação em cada um dos contextos onde a automação se aplica.

Uma vez que é necessário um balanço entre os estímulos de atenção e sua intensidade para se retardar o processo de complacência, é necessário primeiro um entendimento das reais necessidades e da situação do usuário do sistema. Propõe-se então uma abordagem mais centrada no humano para o projeto de interface, e não apenas orientada ao funcionamento da automação em si e seus possíveis cenários de falha. Considerando as necessidades do humano, ponderando-as à luz das especificidades da tarefa desenvolvida pelo sistema, é possível adaptar a teoria para adequar o controle de estímulos a cada situação, retardando assim o processo de complacência. $16^{\circ}$ Ergodesign - Congresso Internacional de Ergonomia e Usabilidade de Interfaces Humano Tecnológica: Produto, Informações Ambientes Construídos e Transporte

$16^{\circ}$ USIHC - Congresso Internacional de Ergonomia e Usabilidade de Interfaces Humano Computador

CINAHPA | 2017 - Congresso Internacional de Ambientes Hipermídia para Aprendizagem.

\section{BIBLIOGRAFIA}

Banks A.V., Stanton, N. Keep the driver in control: Automating automobiles of the future. Applied Ergonomics, No 53, P389-395. Elsevier. 2016.

Carvalho V.R. et al. Human Factors Approach for Evaluation and Redesign of Human-System Interfaces of a Nuclear Power Plant Simulator. Displays. N 29. p273-284. Elsevier. 2008.

CHAPANIS, A. Research Techniques in Engineering. Segunda Edição. Jhons Hopkins Press. Baltimore - Maryland. 1962.

Degani, A. Taming HAL: Designing Interfaces Beyond 2001. Palgrave Macmillan, 2004. 320 ISBN 031229574X.

Dekker, S. Ten Questions About Human Error: A new View of human Factiors and System Safety. New Jersey: Mahwah, 2004.

HSE. Better Allarm Handling. Chemicals Sheet No.6. Health and Safety Executive. 2007

HSE. Out of Control: Why systems Go Wrong and How to Prevent Failure. 2. Noewich: HSE Books, 2003.

Hunziker M. H.L., Afinal, o que é controle aversivo?. ACTA COMPORTAMENTALIA.N 19. P9-19. USP. São Paulo.2011.

Jones, M. L. Effect of Repeated Function Allocation and Reliability on Automation-Induced Monitoring Inefficiency. University of North Florida. 2007.

Lyons J.B. Et Al. Trust-Based Analysis of an Air Force Collision Avoidance System. Ergonomics in Design. 2016

Marstal et al. Collaboration in the Cockpit: Human-System Interaction Beyond the Autopilot. Ergonomics in Design. 2016.

Molloy, R. \& Parasuraman, R. (1996). Monitoring an automated system for a single failure: 


\section{$16^{\circ}$ \\ ERGODESIGN USIHC CINAHPA}

$16^{\circ}$ Ergodesign - Congresso Internacional de Ergonomia e Usabilidade de Interfaces Humano Tecnológica: Produto, Informações Ambientes Construídos e Transporte

$16^{\circ}$ USIHC - Congresso Internacional de Ergonomia e Usabilidade de Interfaces Humano Computador

CINAHPA | 2017 - Congresso Internacional de Ambientes Hipermídia para Aprendizagem.
Vigilance and task complexity effects. Human Factors, 38(2), 311-322.

MORAES, A; MONT’ALVÃO, C. Ergonomia: Conceitos e aplicações. 4 Edição. Rio de Janeiro. 2AB. 2012.

Norman, D. The Design of Future Things. Basic Books, 2009. 240 ISBN 0465002285.

Oakley, B., Mouloua, M., \& Hancock, P.A. (2003). Effects of automation reliability on human monitoring performance. Proceedings of the Human Factors and Ergonomics Society, 47, 188190.

Parasuraman, R., Molloy, R., Mouloua, M., \& Hilburn, B. Monitoring of automated systems. In R. Parasuraman \& M. Mouloua (Eds.), Automation and human performance: Theory and applications. Mahwah, NJ: Lawrence Erlbaum. 1996

Parasuraman, R.; B., S. T. A Model For Types and levels for Human interaction with Automation. IEEE Transactions on systems, v. 30, 2000.

Parasuraman, R.; Dietrich, H. M. Complacency and Bias in Human Use of Automation: An Attentional Integration. Human Factors, v. 52, p. 29, 2010.

Parasuraman, R.; Sheridan, B. T.; Wickens, D. T. Situation Awareness, Mental Workload, and Trust in Automation: Viable, Empirically Suported Cognitive Engineering Constructs. Journal of cgonitive engineering and decision making, v. 2, p. 20, 2000.

PRARAZURAMAN, R. \& SHERIDAN, T.B. Human-Automation Interaction. HFES. USA. 2006.

Prinzel III. Examination of Automation-Induced Complacency and Individual Difference Variates. NASA. 2001

PROCTOR; VU. Task Analisys. in: Salvendi, G. Handbook of Human Factors and Ergonomics. New jersey. Willey. 2006.
Ray. B. A. Strategy in Studies of Attention: A commentary on d. i. mostofsky's attention: contemporary theory and analysis. Journal of the Experimental Analysis of Behavior. 17 p293-297. 1972.

Reynolds G.S., Limpo, A.J. Attention and Generalization During a Conditional Discrimination. Journal of the Experimental Analysis of Behavior. N 12. p911-916. 1969.

RITTER E. F. \& BRAXTER D. G. Fundations for Design Usercentered Systems. New York. Springer. 2014.

Skinner, B. F. Ciência e Comportamento Humano. São Paulo: Martins Fontes, 1953.

Wickens, D.C. et al. Stages and Levels of Automation: An Integrated Meta-analisys. Procedubgs of Human Factors and Ergonomics Society 54th Anual Meeting. 2010. DOI: $10.177 / 154193121005400425$.

YOUNG, M. S. Ergonomics issues with advanced driver assistance system (ADAS). In Gikkas, N. Automotive Ergonomics: DriverVehicle Interaction. Taylor \& Francis, New York. 2013.

\section{Agradecimentos}

Gostaria de agradecer à CAPES pela bolsa de pesquisa que tornou este estudo possível. Gostaria de agradecer a Maurício Cardoso pelo suporte na revisão de literatura.
Realização:

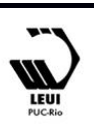

